Danilo Santos de Miranda

- Graduado em Filosofia, Ciências Sociais e Administração

- Especialista em gestão empresarial pelo International Institute for Management Development, Suíça

- É diretor geral do Sesc-São Paulo desde 1984

- É conselheiro do Museu de Arte Moderna de São Paulo (MAM-SP), da Fundação Itaú Cultural e do Museu de Arte de São Paulo (MASP), entre outras entidades

- Foi presidente do Conselho Diretor do Fórum Cultural Mundial (2004) e presidente da comissão que organizou o Ano da França no Brasil (2009)

- Autor de 0 parque e a arquitetura: uma proposta lúdica (2001)

- Organizador de Ética e cultura (2004)
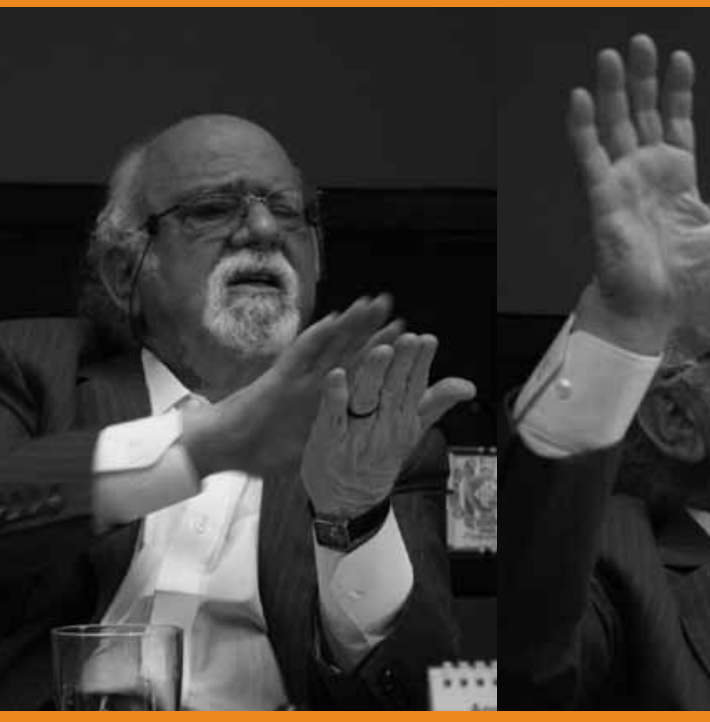


\section{Cultura como fim e por princípio}

Culture as an end and principle

Cultura como fin y por principio

\section{entrevista \\ Danilo Santos de Miranda}

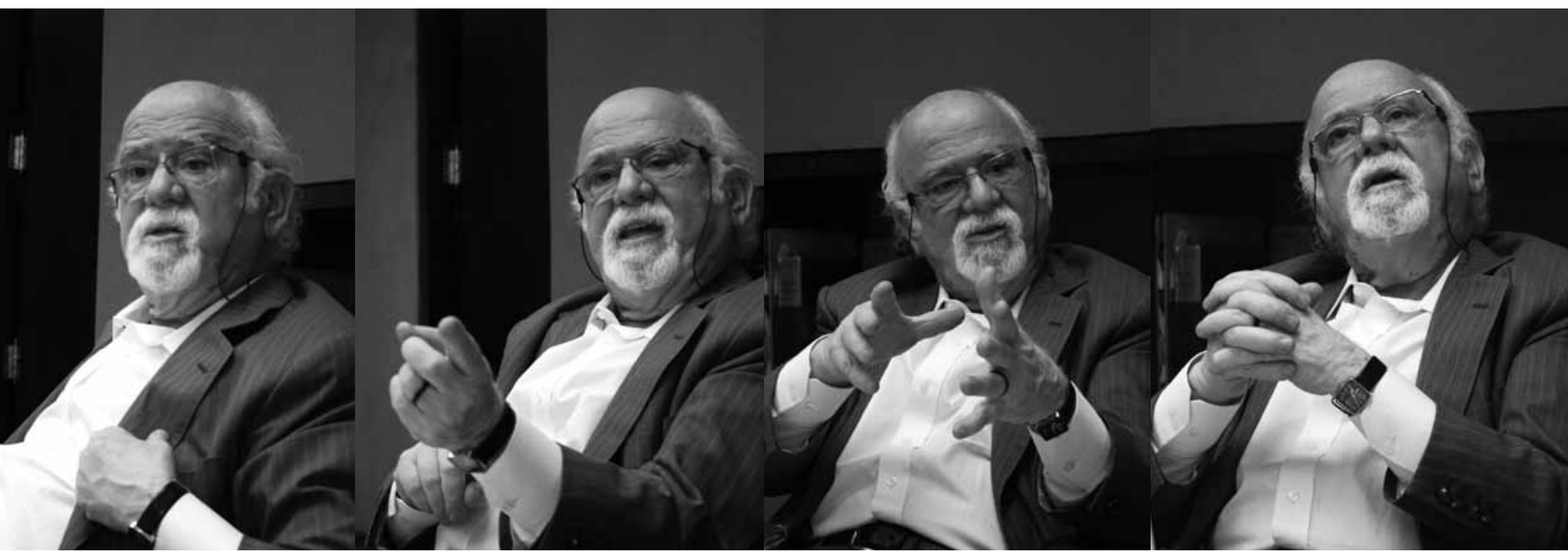


ela janela do edifício sede do

Sesc-São Paulo, no bairro do Belenzinho, pode-se ver o grande espaço que será inaugurado ainda em 2010 e atenderá a mais de 5 mil pessoas por dia. Esta é mais uma unidade a ser entregue e que se soma a mais oito novas programadas entre construção e reformas no Estado de São Paulo. Esse clima de crescimento sustentado em planejamento de longo prazo - para Danilo Santos de Miranda ampliações das construções devem acontecer somente quando a estrutura física está em ordem, do contrário não faz sentido - fez do diretor geral do Sesc-SP um dos nomes mais respeitados do país na área de cultura. Gestor focado em cultura e lazer, ele recebeu Organicom para contar como há décadas passou a entender que a ocupação do tempo livre das pessoas é uma tendência irreversível e deve ser tratada como diferencial no crescimento e fortalecimento de um país.

Já nos anos 1960 e 1970, Danilo atuava em atividades vinculadas a manifestações culturais e comunitárias no interior de São Paulo. Talvez isso tenha sido essencial para que ao longo da carreira transformasse o Sesc-SP em benchmark como entidade promotora de cultura em nosso país. Para ele, cultura "está presente no dia a dia das pessoas em todo momento" e isso deve ser visto de forma inclusiva, entendendo-se que os espaços de lazer também devem ser valorizados como momentos culturais.

Há mais de quarenta anos Danilo Miranda, que estudara em um colégio de jesuítas, veio de sua cidade natal Campos, no norte do Estado do Rio de Janeiro, para a cidade de São Paulo fazer o curso superior: primeiro Filosofia, depois Ciências Sociais e ainda Administração, área na qual se especializou na Suíça. A formação humanística desde a infância deu-lhe base para entender melhor da natureza humana e poder investir sua energia ao longo da carreira para materializar seus ideais.

Embora tenha dito durante a entrevista que ao longo da vida não teve a intenção de seguir carreira acadêmica, o que se pode ver ao longo da conversa de duas horas na sede do Sesc-SP, foi mesmo uma aula sobre a história, os caminhos e o futuro da cultura no país, na qual dosa muita serenidade e paixão.

Organicom-O senhor imaginava, em 1968, quando ingressou, por meio de concurso, no Sesc-São Paulo, que iria se envolver de maneira tão profunda com a cultura brasileira?

Danilo Miranda - Eu prestei concurso na perspectiva realmente de entrar, alguém me recomendou e disse "Você tem condições, filho. Você pode entrar". Mas à medida que eu ia passando no concurso, que era um concurso de pelo menos quatro ou cinco fases, eu imaginava que não ia continuar, que estava decidido que eu não tinha chance. Primeiro foi uma prova imensa de conhecimentos gerais, atualidades, sobre o mundo. $\mathrm{O}$ mundo das artes, da cultura, do esporte, da política, da economia, da antropologia, da política. Entrei, e aí me descobri em uma instituição que procurava uma ação de caráter comunitário no interior de São Paulo e na capital, 
visando juntar unidades em torno de determinados objetivos.

Organicom - E quais eram esses objetivos?

Danilo Miranda - Basicamente, dois grandes campos: um mais cultural, no qual se fazia uma espécie de seminários, tertúlias literárias, cinema, teatro, música, enfim você lidava com isso de uma forma a juntar tudo o que se fazia na comunidade e tentava-se articular esses movimentos. E o outro no campo da atividade física, em que alguém organizava uma grande olimpíada, com grandes jogos, atividades, juntando tudo. Eram esses dois campos. Mas se fazia de tudo em torno de algumas questões. Por exemplo, nos juntávamos e dávamos cursos de administração, relações humanas, relações públicas, mas isso tudo no fundo era a maneira que se tinha para juntar aquele povo, para organizar uma espécie de festival, um festival cultural, e também uma atividade de caráter físico. Era uma coisa que trazia um agito na comunidade, sobretudo com os jovens.

Organicom - O senhor ficou um periodo no Senac e depois retornou ao Sesc-SP. O que encontrou nesse retorno?

Danilo Miranda - Nesse tempo todo eu mantinha contato com o Sesc, que vinha crescendo e evoluiu. Nos onze anos em que fiquei fora do Sesc, ele ganhou dimensões importantes, criou unidades que não tinha, desenvolveu grandes trabalhos. Foi relativamente fácil e simples pegar toda aquela evolução que o Sesc-SP teve naquele período e ampliar isso de uma forma mais objetiva, direta, ligada ao mundo da cultura de modo geral. E, sobretudo, deslocando um pouco a discussão sobre o lazer e o tempo livre, que era um pouco a filosofia do Sesc, para a ocupação do lazer e do tempo livre numa perspectiva cultural. E o cultural ganhando não apenas a dimensão de valorização das artes, mas trabalhando o desenvolvimento, a transformação e a melhoria do ser humano. E aí o cultural tem essa conexão com a arte no mundo do simbólico, mas tem uma conexão com o mundo do físico, à medida que estabelece valores para a atividade física como uma atividade importante para o bem-estar social. Estabelece relações sociais importantes, porque trabalha a vinculação do Sesc com a sociedade e com questões como a do idoso, da criança, das categorias menos atingidas.

Organicom - Quais são as metas, os desafios para os próximos anos para o SescSP, o que vocês esperam?

Danilo Miranda - Uma instituição como a nossa tem que ser abrangente e duradoura e tem que ter sempre uma perspectiva estratégica de futuro, então nós não estamos parados. Ela tem uma perspectiva de caráter fisico, material, com unidades novas como a que está sendo terminada aqui e outras na capital, no interior. Então fisicamente nós temos um plano de expansão importante baseado na nossa capacidade de crescimento, objetivo. Nós não estamos fazendo loucuras para depois dizer "Como é que vamos fazer pra manter isso?”. Não adianta também imaginar que a gente vai triplicar o tamanho em dez anos. Isso não existe. Não há dinheiro para isso. O Brasil é um país que cresce, cresce mesmo e a gente é otimista 
com relação a esse crescimento. Nós somos inevitavelmente um país que é emergente já há algum tempo. Não nos descobrimos emergentes agora. Vamos crescendo gradativamente, mas vamos crescendo. Então, do ponto de vista material existe esse fenômeno e do ponto de vista conceitual existe uma questão fundamental que é a seguinte: o tempo livre e o tempo dedicado às atividades não-materiais cresce all around the world. E uma das características desse desenvolvimento é dar liberdade a esse crescimento, a possibilidade que se tem de usar melhor o tempo de maneira autônoma. Isso é o fundamento da ação que realizamos no Sesc.

Numa cidade com atividade intensa se sente a necessidade de outros universos. Ou é a igreja ou é o clube ou são os amigos... alguma atividade cultural. Então, às vezes a pessoa fala: "Mas o Sesc daqui a pouco pode não existir, vem uma lei aí e acaba". Não, não. O que nós fazemos, alguém vai ter que fazer. Porque a sociedade, hoje, tem isso cada vez mais claro e exige isso.

Organicom-Como o senhor acha que, hoje, a sociedade se mobiliza para a efetivação da cultura? E como percebe o nosso cenário cultural?

Danilo Miranda - A cultura é uma manifestação nobre do ser humano, independentemente de ele querer ou não, de saber ou não que o faz. A cultura está presente no dia a dia das pessoas em todo momento. A cultura é tudo aquilo que se diferencia do natural e da natureza. Então, está presente de uma maneira absoluta, muito mais forte, mais intensa do que possamos imaginar e tem a ver com o humano, tem a ver com valores humanos, se liga à busca de melhorias, de desenvolvimento, de avanço, de conforto, de prazer. A arte, diferentemente de outros componentes que fazem desenvolver o mundo da cultura, tem uma conotação absolutamente própria. Ela lida com o mundo simbólico, da representação, no qual não se lida com a mesma funcionalidade do mundo da tecnociência, por exemplo, que se desenvolve com o objetivo de resolver questões, de melhorar a vida, de estabelecer melhores condições, enfim, de crescer. A arte não necessariamente está vinculada a esse objetivo, pois não precisa se preocupar com a melhoria de vida das pessoas, no sentido restrito. Acaba como consequência sim, mas não é algo que está embutido na essência da sua proposta. Arte é a manifestação, óbvia, da capacidade humana de imaginar, de crescer, de se desenvolver, de criar fantasias, de ampliar a sua condição e seu repertório, para entender melhor a realidade à sua volta. Ela tem uma função absolutamente elevada, acima do material: é valorização do espírito, sem nenhuma conotação religiosa, o que vai além do material, que está em nossa

\section{$\boldsymbol{\nabla}$ A cultura tem \\ a ver com valores \\ humanos, se liga \\ à busca de \\ desenvolvimento, \\ de avanço, de conforto, \\ de prazer}


inteligência, na capacidade de entender as conexões mais amplas e menos óbvias. Então, a cultura é fruto, toda ela, de momentos.

No Brasil, hoje em dia, temos uma situação absolutamente favorável de um lado e desfavorável de outro. Favorável, à medida que há consciência e identidade maiores. As pessoas têm capacidade de enxergar-se melhor, de valorizar sua vida, o que fazem, o que se conhece, seu jeito de ser. Isso é importante pelo processo político, econômico, social, cultural que nós vivemos. Por outro lado, temos questões práticas: o que a cultura, essa cultura mais artística exige? $\mathrm{O}$ entendimento claro dos papéis da sociedade, do Estado, do privado, e esses papéis estão muito confusos, estão muito trocados, muito embaralhados.

Houve um processo - que acho inadequado - de valorização do caráter privado do financiamento das sociedades artísticas. Mesmo privado, às vezes não é apenas com dinheiro privado, mas privado também com dinheiro público, à medida que parte desse incentivo fiscal é decidido pelo privado e não pelo público. $\mathrm{O}$ incentivo fiscal é dinheiro público. Então deveria haver uma negociação, um pacto mais organizado e isso, nesse momento, se discute melhor. Mas o que mais me incomoda é o fato de se reduzir o financiamento de incentivo à cultura a esses mecanismos de incentivo fiscal, quase que exclusivamente.

Instituições como a nossa, que tem maior liberdade, têm vínculo com a iniciativa privada, com as empresas, mas é um vínculo organizado e definido: "vocês fazem isso, nós faze- mos aquilo”. O Sesc é mantido por instituições privadas, as empresas, a contribuição de empresas. E uma contribuição obrigatória, embora de caráter privado, mas obrigatória por lei. O que significa dizer que o Sesc é uma instituição não apenas financiada, mas também administrada por representantes das empresas. Só que essa representação não se dá em nome de nenhum nome ou marca, ou interesse privado particular, mas se dá em nome do interesse público. Então, ela acaba cumprindo uma missão de caráter público. Isso é uma visão importante para o entendimento do "Sistema S" que fazemos questão de levar muito a sério. São, portanto, instituições privadas que atendem a interesses públicos; e isso faz com que a gente cumpra, de certa maneira, a função do Estado. Nós temos uma característica meio complementar à ação do Estado.

Organicom - As leis de incentivo fiscal - a Lei Rouanet, principalmente, que está sendo discutida, e não sabemos exatamente o que vai acontecer - são politicas públicas de uso privado...

Danilo Miranda - Acabam sendo. E não era para sê-lo, porque lá atrás, quando a lei foi criada, se previa a instância pública muito bem definida e claramente colocada como balizadora, como reguladora de tudo. Isso foi sendo abandonado.

Organicom - O senhor acredita que o Ministério da Cultura hoje teria condições de fazer um processo de redemocratização da distribuição de verbas?

Danilo Miranda - Acho que sim, mas são necessários outros instrumentos 
para desenvolver isso. Acredito que a Lei Rouanet tem que sofrer modificações e estas têm que estar na base, levando em conta alguns aspectos. Primeiro, o interesse público tem que prevalecer. Há ações em que o interesse privado prevalece. Quando prevalece? Quando o lobby, quando as pressões, quando as fundações vinculadas ao interesse privado acabam caindo na força, na dimensão, muito acentuada, para decidir o que fazer, quando fazer, então aí prevalece o interesse privado sim, e aí é condenável. Minha tese é que já há mecanismos na lei para evitar isso, mas há certa recusa, certo receio de se utilizar esse tipo de mecanismo, talvez com receio do Ministério Público, da Justiça etc. É a tal isonomia: se todos somos iguais, absolutamente iguais, então você tem que respeitar todas as posições. Isso é um lado da questão. Mas o outro balizador, além do interesse público, tem que ser o seguinte: sendo uma parceria público-privada - de certa maneira é uma "PPP" -, tem que se levar também o interesse privado nisso de maneira regulada. $\mathrm{O}$ que quero dizer com isso? Que não adianta vir com uma norma pela qual só o interesse público e a instância pública vão decidir sozinhos. Não. Se você quer a colaboração por meio do incentivo fiscal e se, além do incentivo fiscal, você quer uma reciprocidade do incentivado, tem que ter o incentivado participando também de uma instância para poder utilizar esse recurso. E não achar que funcionaria somente por meio de um fundo geral. Há interesse público, então você quer pôr dinheiro nisso? Quer se beneficiar do incentivo? Tem que haver um incentivo aliado a uma reciprocidade de participação da empresa que dá o dinheiro que eles chamam de "limpo", que não é incentivo, dinheiro próprio, dinheiro do resultado, do lucro. Em segundo lugar, tem que se ouvir a empresa. Isso é negociação, é indispensável. Simplesmente só colocando dinheiro no fundo, utilizando de maneira livre, sem dar satisfação, eu acho que não vai dar certo. Por quê? Porque se eu sou incentivado e não participo, me desculpe, mas então não quero ser incentivado: pago meu imposto e usa-se do jeito que governo quiser. Mas, se existe uma lei de incentivo, é porque existe uma intenção de haver algum tipo de negociação.

Organicom - Além do que, hoje temos a interferência da Secretaria de Comunicação Estratégica do Governo na decisão dos projetos.

Danilo Miranda - Isso para empresas públicas. No ano passado fui presidente do Comissariado Brasileiro do Ano da França no Brasil. Então, tive muito contato com esse mundo da atividade cultural. E conseguimos um excelente resultado, foi um ano muito bem resolvido.

Uma das dificuldades encontradas era você juntar o financiamento que provinha de algumas empresas públicas, administradas pelo Estado, vinculadas ao interesse público e ao interesse do Estado, juntar esse financiamento à decisão sobre financiamento que é aquilo que o Estado definia como algo que deveria ser feito. Muito curioso. E em alguns momentos a empresa pública ganha a dimensão do Estado...

Organicom - Como a Petrobras... 
Danilo Miranda - Esse é um bom exemplo. O conjunto de ações que a Petrobras realiza diretamente no campo da cultura, não sei até que ponto cumpre uma perspectiva pública, em que o Ministério da Cultura é o detentor, digamos, dessa orientação política, de política pública. Agora por outro lado, há uma certa curiosidade de se ver também o que de uma grande empresa pública é de fato a sua política de marketing para ampliar seus valores, sua marca, sua imagem e o que é política de cumprimento da Lei Rouanet. E quando essas duas coisas se misturam? Na realidade há duas facetas interessantes aí: Banco do Brasil, Caixa Econômica, Petrobras, Eletrobras e outras empresas são vinculadas ao poder público, mas agem no mercado como se fossem privadas. E, como tal, têm que agir com a mesma política livre e ágil de marketing que as outras usam, o que eu acho perfeito! Os bancos públicos têm que disputar clientes com todos os demais bancos e assim por diante.

Então é preciso oferecer condições favoráveis, fazer publicidade, fazer propaganda na televisão; isso é uma coisa. Outra é o dinheiro que se põe, incentivado, no esporte, na cultura. Porque esse dinheiro tem que fazer parte de uma política diferente daquela. Quando você junta tudo em uma política só, provavelmente não dará certo.

Organicom-Como é que senhorvê esse novo ambiente, essa postura das empresas em exigir contrapartida social vinculada às práticas culturais, às ações culturais?

Danilo Miranda - Eu tenho certa desconfiança de que isso é inadequa-
$\boldsymbol{\Delta} \boldsymbol{\Delta}_{\text {No Sesc, o cultural }}$

ganha não apenas

a dimensão de valorização

das artes, mas trabalha

o desenvolvimento, a

transformação e a

melhoria do ser humano

do. Claro que em determinados programas cabe; em outros, nem tanto. A função do Estado no campo da cultura envolve pelo menos três grandes áreas, três grandes aspectos que devem ser considerados: o primeiro diz respeito à arte pura, à manifestação artística pura, seja ela popular, seja a mais sofisticada possível, seja simples, complexa, não importa. A arte pela arte. O de gente que quer criar, e que precisa de formação, de desenvolvimento, que precisa avançar nesse campo. Então, trabalhos como a Bienal de Arte, grandes festivais, ações amplas como circuitos etc. - a arte que eu não vou dizer consagrada, mas aquela feita no seu sentido mais completo, para aqueles que desejam ou viver da arte ou ter a arte como parte essencial da sua vida.

E ainda aqueles que têm a arte como essência da sua vida também. Eles também em esse papel e há muitos. Por exemplo, um artista de uma pequena cidade do interior que lida com maracatu. O homem trabalha, faz aquilo como representação do seu simbólico e da sua tradição três, quatro vezes por ano. É um operário, mas também é um artista que deve 
ser tão respeitado como qualquer outro, tão importante quanto aquele que aparece no teatro municipal cantando. Essa arte, no sentido mais puro do termo, faz parte de todo um contexto que você tem que perceber; tem que receber atenção, tem que ter escola, infraestrutura para isso.

Existe também outro campo, que é a arte transformadora, porta de inserção social, de inclusão do indivíduo. E essa arte, esse mundo da arte e da cultura é direcionado, sobretudo, àqueles que tem carências e necessidades. É importante que haja programas voltados para esse tipo de público e que recebam incentivos. A ação que se faz, por exemplo, em favelas, na periferia, ação que se faz nas regiões mais carentes. Necessário e indispensável. Embora se misture um pouco com aquele campo anterior, os dois são distintos. Eu não posso chegar para o Paulo Autran dizendo: "Olha, Paulo, não se preocupe. Eu não estou dando pra você, mas eu estou dando para o morro ali que está preparando o teatro... "Não tem nada a ver uma coisa com a outra. Isso foi uma resposta que o Gil (Gilberto Gil, ex-ministro da Cultura) deu uma vez quando o Paulo Autran se queixou de que faltava financiamento para o teatro e Gil falou: "Não, mas nós estamos dando dinheiro para o teatro da favela do Rio de Janeiro". Então, esses dois mundos, claro que eles têm uma conversa, claro que aqueles que estão no mundo consagrado muitas vezes ajudam também a preparar pessoas novas para entrar. $E$ alguns desses que se preparam no mundo das artes, no mundo da inclusão social, acabam se transformando e chegam lá.
Você pega, por exemplo, a banda AfroReggae, que já é profissional e começou batendo lata. Passou de um universo ao outro. Então, é interessante observar essa questão, porque, quando se confunde uma coisa com a outra, a reciprocidade se exige onde? Nesse segundo campo, não naquele primeiro.

Pode haver uma conversa, por exemplo, liberam-se cem mil reais para o Balé Stagium ou para o Cisne Negro se apresentarem. Vai se querer de volta abertura para alguns espetáculos para um determinado tipo de público que precise de ingressos, claro.

Aí tudo bem, há uma reciprocidade inteligente, mas colocar essa reciprocidade como se o que você faz no campo das artes, pura e simplesmente, não é o trabalho educativo, está errado. Então, uma peça de teatro profissional, um balé profissional, um grupo profissional que se apresente, independentemente do público que assiste, ele é educativo, cumpre com uma missão educativa e social, enfim. Só não cumpre uma missão social se você impede que o grande público tenha acesso. E aí, por exemplo, o Cirque du Soleil chegou aí e custava trezentos reais pra entrar... não está cumprindo uma missão social. E foi dinheiro público: se vai dinheiro público é importante reduzir o valor dos ingressos.

Lembro que alguns anos atrás fizemos um evento importante, de alguns grupos de dança financiados pelo BNDES. Eram as meninas de rua, transformadas em bailarinas, e funcionava muito bem. O grupo veio e se apresentou. Mas havia algumas 
$\boldsymbol{\Delta} \boldsymbol{U}_{\text {A função do Estado }}$

no campo da cultura

envolve pelo menos três

grandes áreas: a arte

pela arte; a arte como

essência da vida; e a

arte transformadora desse universo de discussão do campo das artes. E também a questão da exportação: temos produtos culturais absolutamente indispensáveis a serem considerados, como música, teatro, dança e outros que têm um padrão internacional importantíssimo. Como lidar com isso? Como incentivar isso? É função do Ministério da Cultura, junto com a diplomacia do Itamaraty. Eu tinha sugerido a um dos candidatos à presidência da República que estudasse uma espécie de possibilidade de colocar na rede mais importante, digamos assim, de consulados e embaixadas brasileiras no exterior, no escritório, um profissional, alguém cuidando apenas, por exemplo, da questão da música brasileira - que é o produto mais reconhecido no mundo. Vamos usar isso, vamos explorar mais, levar artistas, fazer intercâmbio, transformar isso em um produto que possa ajudar a cultura brasileira, a exportação brasileira, a imagem brasileira. Poderiam fazer de uma maneira organizada. A França tem. Quase todos os países têm um representante de sua música e outro do seu audiovisual só para isso, vinculado aos consulados e aos ministérios, permanentemente. A pessoa está ali para cuidar só disso, por isso eu acho importante.

Organicom - Hoje no conceito de indústria cultural o que se pode perceber de mais significativo são produtos que não oferecem necessariamente espirito crítico ou bom nivel de qualidade - novelas, algumas expressões musicais etc. Além disso a televisão - de penetração incrivel - tem alcance territorial gigantesco, trabalha com o conceito de rede, que acaba influenciando além de tudo as próprias formações culturais locais. Como o senhor 
disse, essas expressões são muito importantes e também começam a dar uma espécie de cara ao Brasil.

Danilo Miranda - Dentro e fora [do país].

Organicom - Dentro e fora, exatamente. Como é que o senhor enxerga isso?

Danilo Miranda - Eu acho um problema essa questão da globalização em geral e dessa nossa globalização. Nacionalizamos tudo. Ela corre esse risco de ser realmente a criação de uma linguagem que acaba não tendo a ver com o jeito de ser, de falar, de sentir, de comer, de vestir, enfim, o Brasil é múltiplo, o Brasil é diversificado, o Brasil tem essa característica muito forte, não é? Não temos uma cultura brasileira, temos culturas brasileiras espalhadas de norte a sul do país.

Organicom - No Rio de Janeiro até se fala de Secretaria "das Culturas".

Danilo Miranda - Lá se trabalha com isso, com essa ideia. E há os que trabalham com isso de forma mais intensa, sobre o multiculturalismo brasileiro. Realmente não existe somente uma cultura, porque a nossa formação é variada, de influências múltiplas. Temos situações geográficas muito distintas que fazem parte desse condicionamento - a influência regional, antropológica e ambiental. Floresta é uma coisa, planalto, outra, praia, outra. Enfim, nossa cultura é variada, tem alguns pontos comuns, temos valores que foram importantes, como a unificação da língua, por exemplo. Isso foi importante no Brasil em termos de comunicação fácil, diálogo de norte a sul, do Amapá ao Rio Grande do Sul é absolutamente inteligível. Podia não ser, nós podíamos ter feito prosperar a língua geral que era uma língua meio tupi-guarani no início do século XVIII. Se a Corte não tivesse vindo para o Brasil em 1808 e imposto o ensino da língua portuguesa para valer, nós teríamos uma outra realidade.

Esses elementos todos fazem do Brasil um país relativamente unificado de um lado e diversificado de outro em suas diversidades. Então, eu acho muito arriscado de fato essa imposição que vem do mundo militar: você sabe que a grande rede de televisão brasileira surgiu e se ampliou no momento da ditadura e isso, de alguma forma, pensado ou não, estrategicamente elaborado ou não, cumpriu uma missão de unificar esse país, com vantagens e desvantagens. E uma dessas questões é essa influência cultural, sobretudo no Rio de Janeiro, onde está a 'matriz' e o local, o jeito de ser, de falar, de vestir, de pensar, de olhar, de se pentear do Rio de Janeiro. Eu diria, hoje, um pouco mais diversificado. Agora acho que grande parte das pessoas que estão ali fazendo isso são do Brasil inteiro, inclusive de São Paulo também. Mas acho lamentável, pois o equilíbrio é o fundamento da administração em geral e da administração cultural em particular.

Administrar não quer dizer ser a favor disso de uma forma ou de outra, mas administrar é considerar aspectos contraditórios e tomar decisões. Quando se decide sobre qualquer coisa, há uma ou outra opção, e às vezes essas opções são contraditórias entre si e se opta por uma delas. No campo da cultura isso é importante. Agora, sem dúvida nenhuma, a maneira mais 
sofisticada ainda é tentar conciliar aspectos diferentes. Como é que uma ação cultural numa instituição como a nossa ou em outras pode funcionar? Quando você equilibra aquilo que vem de fora com aquilo que é produzido dentro, o que é centralizado com o que é autônomo, o novo com aquilo que é velho, o globalizado com o regional, local. Falta na nossa legislação de maneira mais clara, a obrigatoriedade - já existente em outros lugares do mundo - de as grandes redes de televisão, por exemplo, manterem uma programação autônoma local com uma programação global, obrigatoriamente. Isso é indispensável. Indispensável! Existe, mas há subterfúgios: pode ter de madrugada algo local e se diz que você está fazendo esse equilíbrio. A coisa tem que ser honesta, uma coisa equilibrada.

De certa maneira, essa troca não é negativa se você consegue manter o próprio. Eu não me importo se a gente considerar a necessidade de abrir janelas para todo lado. E nós usamos uma cultura muito intensa na programação em que você contempla o que é feito aqui, mas abre muitas janelas para o que vem de fora. E faz esse diálogo permanentemente.

Um dia desses ouvi uma palestra do Teixeira Coelho [professor da ECAUSP] em que ele dizia que normalmente o global é o moderno e o local é o atrasado. Não é isso, em minha opinião, com todo o respeito. Acho que há local moderno e há global atrasado. Mas a essência das questões, o que vem de fora geralmente propõe avanços com mais frequência do que aquilo que vem de dentro. No mundo da cultura isso é interessante.
Mas de qualquer forma o diálogo entre o local e o global é o segredo para administrar. Então falta aos administradores uma perspectiva de formação para a gestão dos processos culturais de maneira um pouco mais aprofundada. Onde há conhecimento, história, elementos básicos da formação do conhecimento humano, que sejam colocados de maneira intensa para que a gente possa estabelecer metodologias, por exemplo, local e global: como lidar com isso de uma forma adequada, própria? Ainda precisamos avançar muito na questão dos estudos, sobretudo no campo da gestão dos processos culturais e comunicacionais.

Organicom - Falando em gestão, já houve rumores no setor cultural e artístico de que o senhor já fora convidado para ser ministro da Cultura uma ou duas vezes.

Danilo Miranda - Não. Eu já fui convidado pra ser secretário estadual, mas nunca ninguém que tenha o poder efetivamente ou o o represente: "Olha, nós gostaríamos que você pensasse em ser ou fosse ministro”.

Organicom - E se isso acontecesse e o senhor aceitasse, digamos...

\section{$\Delta$ Não existe somente \\ uma cultura, porque \\ a nossa formação \\ é de influências \\ múltiplas - a influência \\ regional, antropológica \\ e ambiental}


Danilo Miranda - É uma hipótese. Eu não tenho isso no meu horizonte, mas é possível.

Organicom - Mas se fosse, haveria um caminho possivel?

Danilo Miranda - Olha, eu acho que teríamos que pensar em algumas questões básicas de nível nacional. Para mim a questão da administração pública em geral, o ministério, em particular. Mas vale também para as secretarias de educação, de cultura, de planejamento, enfim. O Estado, em suas diversas faces, tem para mim dois papéis fundamentais no momento: tudo isso que eu falei até agora, esses universos cabem ali, inclusive a questão do incentivo. São dois grandes campos. Podem até de alguma maneira ser reduzidos: o primeiro campo é o da infraestrutura. Não existe a possibilidade de você imaginar a cultura acontecendo no ar. Infraestrutura física e uma infraestrutura que eu chamaria de programática, de proposta. A física tem a ver com toda a questão de equipamentos, de instalações espalhadas pelo território inteiro. Os elementos vitais e fundamentais da nossa infraestrutura sofrem uma deteriorização enorme e

\section{$\boldsymbol{\Delta} \boldsymbol{\Delta}_{\text {Ainda precisamos }}$ \\ avançar muito na \\ questão dos estudos, \\ sobretudo no \\ campo da gestão dos \\ processos culturais \\ e comunicacionais}

não há o cuidado e a atenção, a preocupação do Estado de mantê-la. Sem falar do patrimônio histórico, religioso, urbano, espalhado pelo país inteiro. Precisaríamos concentrar um programa nacional muito forte ligado ao elemento da infraestrutura toda. E de alguma forma proibir, impedir qualquer construção nova sem levantar o que foi derrubado. Não tem cabimento eu criar uma sala de concerto nova se existe outra sala de concerto que está, não sei onde, caindo aos pedaços. "Ah, mas aquele não serve, não é suficiente". Tudo bem: vamos resolver lá, depois cuidar do outro.

Organicom - Reforma não dá voto...

Danilo Miranda - Não dá voto. E se a cultura for se preocupar com essa questão de voto,.realmente o ministro da cultura não vai ser puxador de voto nunca.

\section{Organicom - Nem vai ao palanque.}

Danilo Miranda - Nem entra, não é chamado. O segundo aspecto da cultura para mim se chama fomento, no sentido mais amplo da palavra, que quer dizer uma política nacional voltada para o desenvolvimento das artes em geral. Atividade cultural no país inteiro. Fomento significa pôr incentivo fiscal ou direto, juntar força, cursos, concursos, festivais, ação efetiva em nível nacional que possa estabelecer toda uma política pública em que a música, o teatro, o cinema sejam valorizados. Como? Realizando uma série de circuitos, de ações efetivas, juntando as pessoas. No Sesc temos um pouco isso - numa escala pequena, mas em nível nacional. Por exemplo, temos um circuito de teatro no Sesc, chamado "Palco giratório" que 
pega ações culturais, sobretudo teatro e dança, e vai circular pelo Brasil levando grupos do Rio Grande do Sul ao Mato Grosso, de São Paulo ao Amapá, do Rio de Janeiro a Goiás, fazendo o maior festival de artes cênicas do país! Chega a oitenta, cem cidades, quarenta a cinquenta apresentações e faz circular, algumas mais completas - como no caso de São Paulo, o festival com todas as manifestações - e outras menores, mas de qualquer forma faz uma espécie de antena, de satélite que vai circulando e fazendo bem. Isso é função do Estado: estou dando um exemplo de fomento. Além disso, você pode fazer algo parecido no campo da música, do teatro, da literatura. Nós temos que incentivar a leitura. O livro ainda é o grande suporte. Mas, de qualquer forma, políticas voltadas para a literatura, o cinema, o teatro, para as artes visuais, para a arte eletrônica. Esses dois grandes campos supõem leis de incentivo, parceria público-privada, uma ação do Estado, efetivamente, com recursos do tesouro. Porque há uma mentalidade de que a cultura não precisa usar recursos do tesouro, de que o mercado resolve. Não resolve! O mercado resolve o que interessa ao mercado e o ministério, o que interessa para formação, para desenvolvimento, para educação etc.

Organicom - E antes era um só ministério (da Educação e da Cultura).

Danilo Miranda - Era um só. Eu sou daqueles que têm saudades de "um só”, mas de um lado. Por quê? Porque o "só" participava da reserva constitucional. Você tinha uma parte do dinheiro vinculada à cultura nos orçamentos públicos. Entrava no mundo da educação-cultura, e a cultura entrava ali como passageira clandestina, o que a beneficiava nessa reserva constitucional para a educação. Como se passou a considerar a educação uma coisa e a cultura outra, eu não vejo como problema para efeito de administração de processos, porque poderia haver um Ministério da Cultura separado, mas não poderia havê-lo do ponto de vista conceitual. Então, teria que haver uma articulação efetiva, uma ação conjunta. Isso não existe. Vale para cultura e para educação física também. O Ministério dos Esportes assumiu a educação física, que é um campo importante para a educação e acabou sendo desvinculado, de alguma forma, do mundo da educação também. Sabe, uma coisa é você dividir para administrar melhor, outra coisa é rachar conceitos. Isso não tem cabimento. O ministro, o homem da cultura tinha que estar presente em todas as ações do governo. Não que ele devesse decidir sobre saúde, transporte, educação, justiça. Não. Mas ele teria que estar vinculado a todos esses aspectos da administração, de modo a permitir que a ação cultural estivesse presente, para que o efeito desses programas, dessas políticas fosse maior. Quer dizer que qualquer ministério que se envolvesse com o mundo da cultura teria algum envolvimento dele ou de alguém dele para discutir a questão. Por exemplo, a administração penitenciaria ou os hospitais resolvem criar uma biblioteca em cada estabelecimento. O Ministério da Cultura está junto. Se eu fosse chamado, eu trabalharia com essas ideias. 